\title{
0 geco e os cabelos de Sansão
}

Este artigo sobre o geco* é o segundo publicado depois do "acordo de intercâmbio de artigos" firmado entre as duas organizações de polímeros brasileira e italiana (ABPol e AIM) conforme noticiado na nossa edição de Abr-Jun 2006, sendo que o mesmo foi editado no AIM Magazine em Dezembro de 2004. A parte interessante se relaciona ao fato que sempre a natureza sugere aos cientistas idéias para desenvolver novos materiais ou novas estruturas. De um lado eles levam grandes vantagens, do outro lado se apercebem que a natureza tem recursos inalcançáveis.

Acontece freqüentemente que, quando a ciência descobre um segredo da natureza e acaba replicando-o, abre-se uma vastidão de possíveis aplicações tecnológicas, mais ou menos avançadas, em seguida a essa descoberta.

Este é, sem dúvida, o caso referente a um inócuo réptil (Figuras 1a e 1b) da família dos Geconídeos, cuja habilidade mais fascinante, objeto de interesse científico, é aquela de ser capaz de sustentar-se e caminhar sobre qualquer tipo de superfície, mesmo com a cabeça para baixo; habilidade que lhe permite, por exemplo, dependurar-se com uma pata só num teto de vidro perfeitamente limpo.

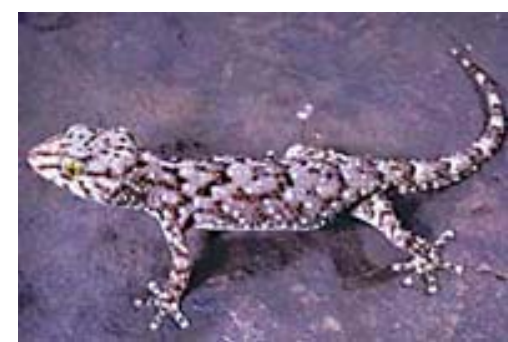

(a)

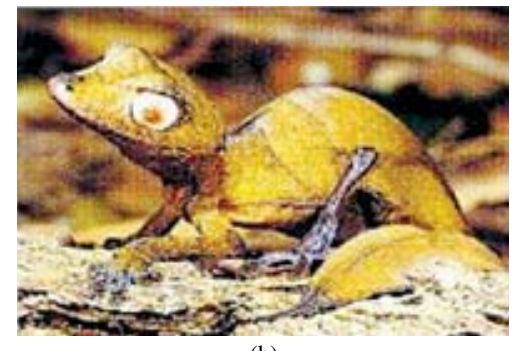

(b)

Figura 1. Dois diferentes exemplares de geco ( $\mathrm{a}$ e b).

Se isto não parecesse suficientemente surpreendente podemos acrescentar que, segundo as avaliações teóricas de vários grupos de pesquisadores, o geco possui uma força atrativa mil vezes maior daquela necessária para sustentar o próprio peso: possui, portanto, aquela que poderíamos chamar "uma força de Sansão!"

Essa associação parece particularmente apropriada dado que exatamente nos "cabelos" se encontra o segredo, recentemente descoberto, da capacidade do geco de caminhar e galgar sobre qualquer tipo de superfície: vertical, horizontal, lisa ou áspera, com características lipófilas ou hidrófilas, na pressão atmosférica ou no vácuo. Tudo isso alcançando velocidades de até $1 \mathrm{~m} / \mathrm{s}$, muito altas considerando que se trata de um animal, cujo representante com maiores

*O geco é da familia de répteis da Subordem Lacertília da ordem Squamata dimensões não supera $62 \mathrm{~cm}$ de comprimento (aquele com as menores dimensões, ao contrário, mede só $18 \mathrm{~mm}$ e é o menor réptil do mundo).

\section{Cabelos sob as patas}

Segundo as recentes pesquisas de K. Autumn, B. Full, A. Geim e de outros pesquisadores, as centenas de milhares de setae a base queratínica que constituem a cobertura de cada pata (Figura 2a), e as centenas de spatulae com as quais termina cada dedo, constituem os apêndices flexíveis que o animal usa para aderir à superfície sobre a qual se encontra.

Se pudéssemos replicar adequadamente este mecanismo de adesão, as aplicações tecnológicas seriam inumeráveis e pertenceriam às mais variadas disciplinas: da robótica espacial até àquela estudada para missões de salvação nos terrenos impérvios, das fitas adesivas utilizáveis em um número indefinido de vezes, até aos equipamentos para apaixonados de free climbing.

Mais em detalhe, cada pata deste tipo de réptil possui uma estrutura lamelar (Figura $2 \mathrm{~b}$ ) terminante com setae
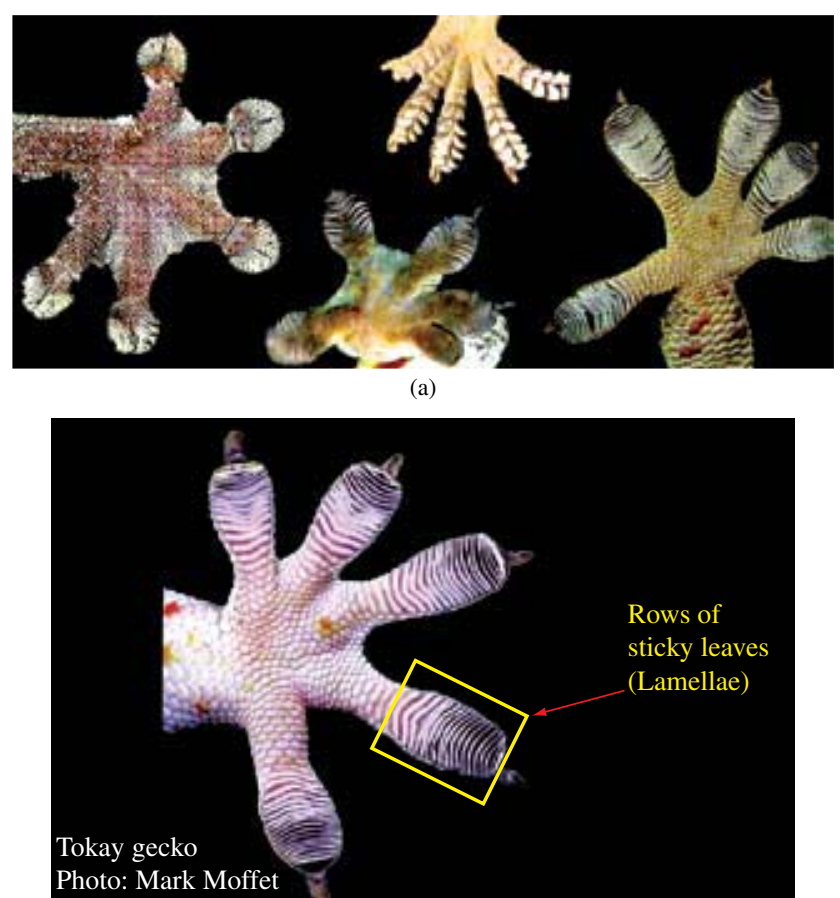

(b)

Figura 2. Diferentes tipologias de patas de geco, todas com estrutura lamelar (a); Em (b) as lamelas são evidenciadas. Fonte: http://www.lclark.edu/ autumn/climbing/climb.html. Copyright (c) 2000, Kellar Autumn. 


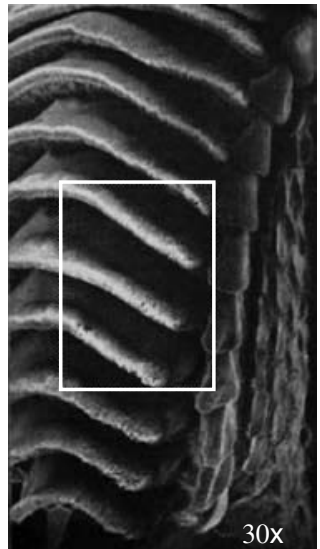

(a)

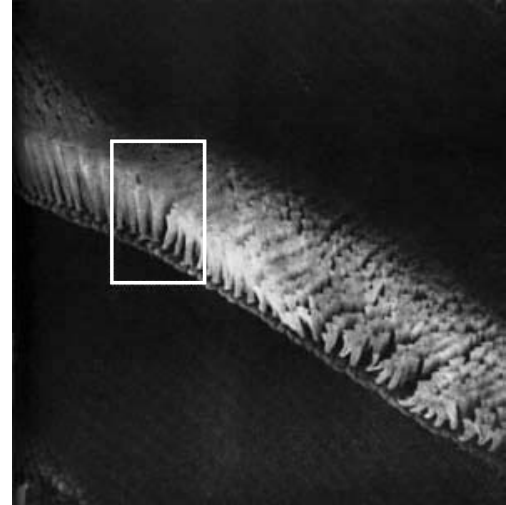

(b)

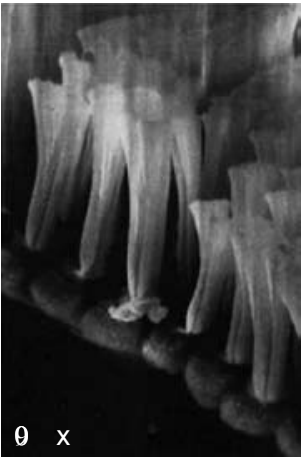

(c)

Figura 3. Ampliação de setae (a) e de spatulae (b) das patas do geco. O segundo é uma ampliação de 270x. Em (c) ampliação de 900x. Fonte: http://www.lclark.edu/ autumn/ climbing/climb.html. Copyright (c) 2000, Kellar Autumn.

a base queratínica, com uma densidade avaliável de 5000 cada $\mathrm{mm}^{2}$. Elas têm um comprimento que varia entre $30 \mathrm{e}$ $130 \mu \mathrm{m}$ e um diâmetro de 200-500 nm. Através da microscopia eletrônica foi possível investigar mais em profundidade a morfologia dessas setae e descobrir que elas apresentam uma estrutura ciliada (Figura 3a). Além do mais, os pesquisadores constataram que cada uma dessas centenas de cílios, de cerca de 0.2-0.5 $\mu \mathrm{m}$ de cumprimento, tem uma forma de espátula (da qual o nome de spatulae; Figura 3b), que as tornam particularmente adequadas à função de íntima adesão a qualquer tipo de superfície.

Devido a esta enorme disponibilidade de spatulae - portanto de força - sob cada pata, como o geco não fica colado a cada passo? A tal propósito, os pesquisadores verificaram que o jeito de andar do animal é tal que se forma um angulo de $30^{\circ}$ entre a superfície e as spatulae, que lhe permite não usar muita força para despegar-se da parede e prosseguir no movimento.

Esse mecanismo é eficaz sobre cada tipo de superfície, exceto para aquelas que não permitem a instauração de forças de Van der Waals eficazes, como, por exemplo, no caso do Teflon. Que o segredo esteja propriamente na formação de milhões de forças de interação intermoleculares fracas foi demonstrado nas pesquisas já mencionadas, que excluíram outros mecanismos como a secreção de fluidos adesivos (o geco não possui glândulas aptas a este escopo) e a sucção, como no caso das salamandras (o mecanismo que estamos examinando funciona também no vácuo).

\section{Um "velcro monocomponente" a base poliamídica}

Prosseguindo com o estudo da especial estrutura das patas do geco, o grupo de A. Geim do Manchester Centre for Mesoscience and Nanotechnology, da mesma Universidade, em colaboração com o Institute for Microelectronics Technology de Chernogolovka na Rússia, chegou a replicar o mecanismo de adesão das spatulae do geco. Sobre um filme baseado na poli (dianidrido-oxidianilina piromelítica) (Figura 4a) com uma espessura de $5 \mu \mathrm{m}$, colocado acima de uma camada de silício, os pesquisadores obtiveram cílios com um comprimento de $2 \mu \mathrm{m}$ e com um diâmetro de 500 $\mathrm{nm}$ (Figura 4b), utilizando a litografia a raio eletrônico sobre um filme de alumínio e transferindo depois o modelo ao polímero, com um sucessivo dry etching em atmosfera de plasma de oxigênio.

Mesmo tendo uma área de contato somente de $0,5 \mathrm{~cm}^{2}$, essa réplica sintética pode sustentar $100 \mathrm{~g}$ de carga pendurados a um teto de vidro. A matriz polimérica flexível pode adaptar-se às eventuais asperezas da superfície de contato e permitir a adesão das spatulae de modo eficaz.

Até hoje esta espécie de velcro de único componente pode ser reutilizada somente 5 a 6 vezes, diversamente do caso das setae do geco que, entre as outras propriedades, são auto-limpantes. Isso parece ser devido ao fato que os cí-

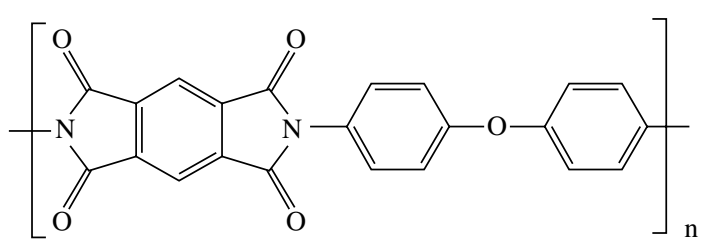

(a)

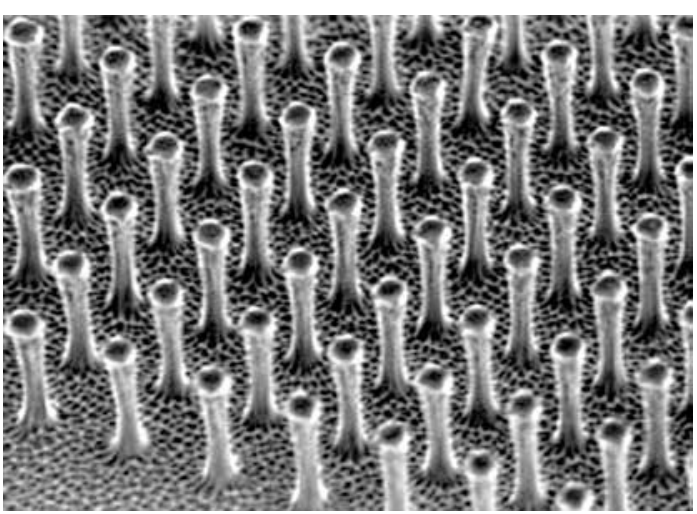

(b)

Figura 4. Monômero da poli(dianidrido-oxidianilina piromelítica) (a); Cílios sintetizados do grupo de Geim sobre o suporte poliamídico (b). (Fonte: http://www. nature.com/cgi-taf/DynaPage.taf?file=/nmat/journal/v2/n7/full/nmat917.html; Geim/ Univ. of Manchester). 


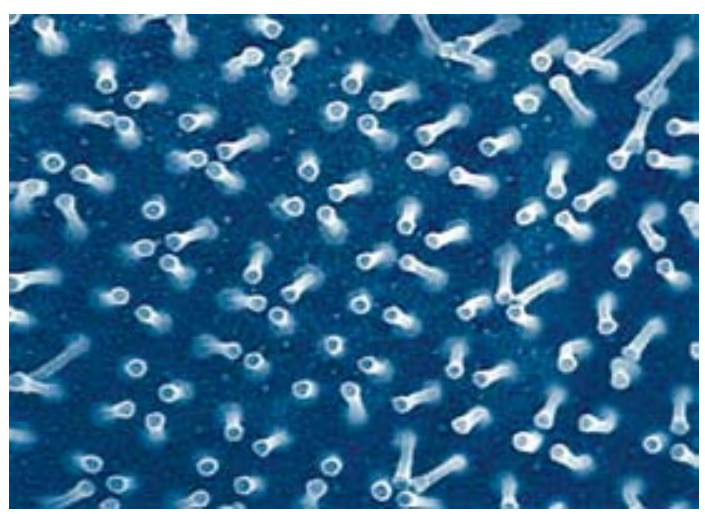

Figura 5. Os cílios sintéticos - comparar com a Figura $4 \mathrm{~b}$ - tendem a se colar uns com os outros depois de serem utilizadas 5 a 6 vezes. Fonte: http://www.nature.com/ cgi-taf/DynaPage.taf?file=/nmat /journal /v2/ n7/full/nmat917.html; Geim/Univ. of Manchester.

lios sintéticos tendem a se colar uns nos outros, como pode ser visto ao se comparar a Figura $4 \mathrm{~b}$ com a foto da Figura 5, tornando-se, portanto, mais disponíveis a aderir sobre a superfície de contato.

A eficácia da adesão dos cílios poliamídicos sintetizados do grupo de Geim depende muito da geometria e da densidade sobre o suporte flexível. Através de numerosos experimentos, concluiu-se enfim que elas devem ter um comprimento ideal de cerca de $2 \mu \mathrm{m}$, um diâmetro de 0.5 $\mu \mathrm{m}$ e uma periodicidade de $1.6 \mu \mathrm{m}$. E ainda, parece que existe uma correlação linear entre a superfície de contato e a força de adesão desenvolvida das setae sintéticas: essa correlação permite concluir que a superfície total média das palmas das mãos (maior de $200 \mathrm{~cm}^{2}$ ) coberta com essas $s e$ tae seja o suficiente para sustentar o peso de uma pessoa de compleição média. Devido ao elevado custo requerido para a produção das setae sintéticas necessárias para cobrir esta superfície (uma ulterior propriedade que os cientistas invejam com respeito às patas do geco consiste, sem dúvida, no fato de possuir uma excepcional tecnologia a custo zero!), o grupo de Geim apresentou uma demonstração em pequena escala (Figuras 6a e 6b) com um objeto familiar particularmente adequado a ilustrar o conceito.

Entretanto, antes que esta tecnologia possa se tornar economicamente acessível em grande escala, os fãs de $M a$ nolo e de Spiderman deverão contentar-se em assistir as evoluções dos seus heróis sem poder emulá-los facilmente.

\section{Bibliografia}

1. www.lclark.edu/ autumn

2. www.cs.man.ac.uk/nanotechnology

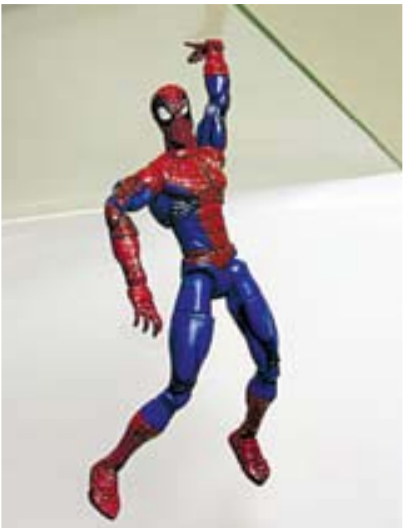

(a)

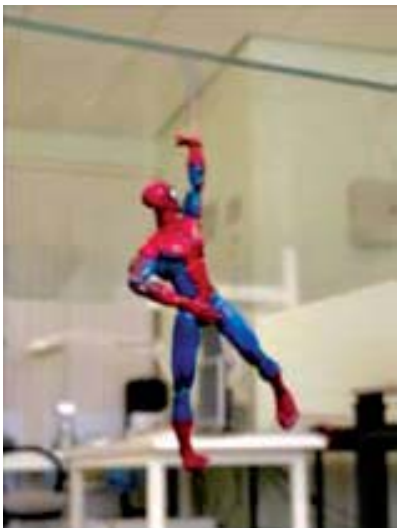

(b)
Figura 6. o grupo de Geim demonstrou a eficácia da réplica sintética pendurando a um teto de vidro um brinquedo de $15 \mathrm{~cm}$ de altura e $20 \mathrm{~g}$ de peso (a) e (b). Fonte: http://www.nature.com/cgi-taf/DynaPage.taf?file=/nmat/journal/v2/n7/full/nmat917. html

3. http://www.nature.com/cgi-taf/DynaPage.taf?file=/nmat/ journal/v2/n7/full/nmat917.html

4. http://news.man.ac.uk/1054290245/index_html

5. www.nanotechweb.org

6. http://news.man.ac.uk/1054290245/index_html

7. http://www.berkeley.edu/news/berkeleyan/2002/09/04_ geco.html

8. http://www.collegenews.org/x609.xml

9. http://www.bbc.co.uk/nature/animals/features/242index. shtml

10. http://www.nature.com/nsu/020826/020826-2.html

11. http://www.apologeticspress.org/docsdis/2003/dc-0305.htm

12. http://www.howstuffworks.com/news-item21.htm

13. http://www.globetechnology.com/servlet/story/RTGAM.20030603.gtgecojune3/BNStory/Technology/

\section{Sobre a autora}

Anna Crestana: Ela se graduou em 2002 em Química Industrial na Universidade de Padova, com uma tese sobre homo e copolimerização das alfa-olefinas com catálise heterogênea Zigler-Natta. Trabalhou na Pirelli em Milão no grupo dos Materiais Inovadores. Atualmente trabalha no centro de pesquisa (R\&D Fabric Care Centre) de uma companhia multinacional líder nos produtos para a casa. Desde 2002 ela colabora com AIM Magazine participando com artigos muito interessantes.

Tradução: Roberto Filippini Fantoni - AIM; cooperação: Silvio Manrich - ABPo 